\title{
Relationship between Academic Emotions, Self-efficacy and mathematics achievement of secondary school students in Central Division, Machakos County, Kenya
}

\author{
Authors \\ Elizabeth N. Mutisya, Dr. Theresia K. Kinai, Dr. Jotham N. \\ Dinga, Dr. Samuel M. Mutweleli
}

\section{Abstract}

The purpose of this study was to determine the relationship between academic emotions and self- efficacy in predicting mathematics achievement of secondary school students. A random sample of 300 form three students (150 males, 150 females) was selected frompublicsecondaryschools in CentralDivision, Machakos County, Kenya. Correlation research design was adopted and data collected using a self report questionnaire. Analysis of examination records was done to obtain data on mathematics achievement. Relationships were determined using Pearson product-moment correlation method while t-test for independent samples was used to determine gender differences between students' academic emotions, self-efficacy and mathematics achievement. Results revealed a significant relationship between students academic emotions, self-efficacy and mathematics achievement. Significant gender differences were found in students' academic emotions and self-efficacy. The findings are useful in helping students to develop control over the process of learning mathematics and attach high 
value to the subject, which lead to development of positive emotions which have a positive correlation to academic achievement.

Key words: Academic emotions, Self-efficacy, Mathematics achievement

\section{Introduction}

Good performance in mathematics is emphasized in education because mathematics is perceived as the foundation for scientific and technological knowledge (Githua \& Mwangi, 2003). Mathematics subject is considered significant for social and economic development and, for this, it is a compulsory subject in many education curricula. For example, in South Africa, it is compulsory in standard 1 to 7 (Kulubya \& Glencross 1997). In Kenya, it is compulsory in primary and secondary levels of education (KIE, 2002). Mathematics is externally examined twice in the Kenyan curriculum; at the end of primary education cycle in the Kenya Certificate of Primary Education (KCPE), and in the Kenya Certificate of Secondary Education (KCSE) at the end of the secondary education cycle. Secondary education is used for placement into further training and career choice. It is, therefore, an important sub-sector of education in the preparation of human capital for development and provision of life opportunities (Onsomu, Muthaka, Ngware \& Kosimbei 2006).

Good performance in mathematics is a requirement for selection into competitive courses such as medicine, 
engineering, architecture and technology (Manoah, Indoshi \& Othuon, 2011). Despite the importance of the subject in the society, there has been a concern about student's poor performance in public examinations. Statistics obtained from Machakos District Education Office reveal that in 2009, 2010 and 2011 mathematics was poorly performed, with approximately $70 \%$ of candidates each year scoring D+ and below. This implies that more than half of total candidates fail in the subject hence missing courses that consider performance in mathematics in higher institutions of learning.

Due to the declining performance in the subject, many studies have attributed its poor performance to both student and teacher factors. These include: teachers subject knowledge (APHRC, 2010), students negative attitude towards the subject (Mbugua, Kibet, Muthaa \& Nkonke, 2012; Manoah, Indoshi \& Othuon, 2011) and students lack of motivation to learn the subject (Githua \& Mwangi, 2003). The current study took a different direction and looked into students academic emotions which have so far received little attention from researchers in Kenya. The main purpose of the study was to determine the relationship between students' academic emotions, self-efficacy and mathematics achievement.

Academic emotions have been reported to influence academic achievement (Pekrun, Goetz, Titz \& Perry 2002a). Emotions are reactions to significant events and objects (Pekrun and Stephens, 2010). Academic emotions thus, refer to students' 
reactions to activities that take place in an academic setting, and which are directly linked to the learning process and its outcome. Emotions can generally be categorized in two: positive emotions and negative emotions (Pekrun, et al.,2002a). Positive emotions include joy, hope and pride while negative emotions are anger, hopelessness, boredom and shame. In an academic setting, emotions can further be classified based on the object of focus, into activity emotions and outcome emotions (Pekrun, et al., 2002a). Activity emotions are emotions experienced during the ongoing learning process. Examples include enjoyment of a mathematics lesson, boredom experienced in a lesson, frustrations and anger experienced when solving difficult mathematical problems. Outcome emotions are determined by the kind of results the student expects to achieve. For example, pride from success or shame from failure. Thus based on this classification, emotions experienced in academic settings are directly linked to the process of learning and the success or failure in academic achievement (Pekrun, 2006). The control-value of emotions theory explains that the perceived control over and value of an activity are central to the arousal of academic emotions and that emotions play an important role in the learning process. The theory further notes that there is a reciprocal causal relationship between emotions and achievement which can create either positive or negative feedback. That is, positive emotions of enjoyment and hope will have positive impact on academic achievement while negative emotions of shame and 
boredom will negatively predict academic achievement. For example, a student who enjoys mathematics lessons will score good grades in mathematics while a student who experiences boredom in mathematics lessons has little interest in the subject hence gets low scores.

The control- value theory also proposes that students can organize and direct their own learning process upon becoming aware of their own competencies and abilities. The control appraisal suggests that student's are able to judge their own competence, expectations and perception of the cause of success or failure in academic work. The value appraisals refer to the importance attached to the learning activity and also the value attached to achievement outcomes such as the perceived importance of attaining success and avoiding failure (Pekrun, 2006; Pekrun, et al., 2002a).

Thus, this theory postulate that a student who experience positive emotions, and highly values learning activities and outcomes tend to be in control of her learning and is more likely to perform better. On the contrary, a student with negative academic emotions and attach low value to learning activities and outcome, has little control over his learning and thus low achievement. Therefore, for a student to perform well in mathematics he or she should be aware of his/her competence in the subject so as to exercise control over it. In addition, the student should attach high positive values on the process of learning the subject and on the expected 
performance.

Another important student factor that influences academic achievement is self-efficacy. Academic self-efficacy indicates the student's belief in their ability to accomplish various school activities. Bandura (1986) expressed that the higher the sense of efficacy, the greater the effort and perseverance in a task. Therefore, students with high self-efficacy beliefs in mathematics are likely to put a lot of efforts even when faced with challenging mathematics tasks. Bandura and Schunk (1991) explored the relationship between self- efficacy beliefs and emotional reactions. Students with low self-efficacy that a task is difficult becomes stressed and develop a narrow vision on how to solve the problem while students with high selfefficacy belief would be more relaxed in solving difficult task because they are confident of their ability to succeed.

Self-efficacy has also been related to a students' interest in school subjects. This interest in specific subjects enables students to put more efforts and become competent in the subjects hence raising their self-efficacy (Hidi \& Ainley 2008). Reports show that self-efficacy is task- specific and varies between subjects. For example, Pajares \& Miller (1997) reported that mathematics self-efficacy is a good predictor of mathematics interest and choice of mathematics related courses. Rahil, Elias, Cheong, Muhamad, Noordin and Abdullah (2006) revealed that academic self-efficacy influences performance in English performance among 
secondary school students. Studies conducted on science and engineering college students (Lent, Brown and Hackett 1994) reported that high self-efficacy influence academic persistence necessary to maintain high academic achievement. Momanyi, Ogoma and Misigo (2011) reported significant relationship between self-efficacy and performance in science subjects while Simiyu (2010) found that students' self-efficacy was significant in influencing performance in mathematics. Based on the findings of previous research it is evident that self-efficacy is pertinent to academic achievement in different subjects. The current study examined the relationship between students' academic emotions and self-efficacy in influencing performance in mathematics. Students' academic emotions and self-efficacy have received little attention from educational researchers as student factors that can influence performance in the subject.

The study objectives were to determine the relationship between students' academic emotions and mathematics achievement, to determine the relationship between students' self-efficacy and achievement in mathematics, establish whether there are gender differences in students' academic emotions and mathematics achievements and finally find out whether there are gender differences in students' self-efficacy and mathematics achievement.

The findings of this study may be significant to students, 
parents and teachers. Students may be able to understand better the role of emotions in the process of learning and be able to manage their emotions so that they can positively influence their performance in mathematics. Students may also realize the need for taking control over their learning process and develop positive value towards mathematics in order to perform well. Parents and teachers may be able to understand better the effects of emotions on students' academic achievement therefore, create stimulating school and home environments that facilitate effective learning. They may also recognize the importance of being good role models to help build students' self-efficacy so as to take active control of their learning. Findings from this study can also serve the purpose of enabling parents and teachers to realize the need to enhance self-efficacy in students to enable them approach mathematics and other school subjects with confidence. In addition, the findings may add new knowledge on factors that influence academic achievement in mathematics. 


\section{Method}

\section{Participants}

The study adopted a correlation research design to determine the relationship between the independent variables (student's academic emotions and self- efficacy) with the dependent variable mathematics achievement. The sample size of the study was 300 form three students ( 150 males, 150 females) selected from five public secondary schools in Central Division, Machakos county, Kenya. The school categories were girls boarding, boys boarding, co-educational boarding, coeducational day / boarding and co-educational day school. In each school a random sample of 60 participants was obtained.

\section{Instruments}

Data was collected using two instruments, a self- report questionnaire and document analysis.

\section{Students' questionnaire}

A self-report questionnaire was used to collect data on students' academic emotions and academic self-efficacy. The questionnaire consisted of three parts. Part I contained items seeking to gather students' personal information comprising of class, admission number, age, gender, school name, school type and residential status. Part II contained the Academic Emotions scale while part III was made of the Academic Self- Efficacy scale. 


\section{a. Academic Emotions Questionnaire (AEQ)}

Students' academic emotions were measured using the Academic Emotions Questionnaire (AEQ) developed by Pekrun, Goetz, Titz, and Perry (2002a). The instrument was adapted to suit the study and was further revised using information obtained from the pilot study to make it applicable to a secondary school situation. The items were also modified to specifically test academic emotions related to mathematics. The scale consisted of 28 items divided into four sub-scales for each of the emotions investigated (joy, hope, boredom and shame). The items on each sub-scale were on a four point scale ranging from 1 = strongly disagree to $4=$ strongly agree. Each sub scale consisted of seven items, therefore sub-scale score ranged from 7 to 28. The score for the entire AEQ scale range from 28 to 112 . Content validity of Academic Emotions Scale was ensured through peer review to include only items that represent the emotions of joy, hope, boredom and shame. The internal reliability of the Academic emotions scale from the pilot study was found to be $\alpha=0.67$ suggesting that the items had relatively high internal consistency; this is so since a reliability coefficient of about 0.70 is considered to be acceptable. 


\section{b. Academic Self-Efficacy Scale (ASES)}

Student's self-efficacy was measured using a 16 items Academic Self-Efficacy Scale adapted from the academic selfefficacy scales developed by Chemers, Hu, \& Garcia (2001) and Zajacova, Lynch, \& Espanshade (2005). Participants responded to a four-point scale ranging from $1=$ strongly disagree to $4=$ strongly agree in rating their agreement with statements reflecting their academic confidence and ability to perform well and succeed in mathematics. The scores of Academic Self-Efficacy Scale (ASES) range from16 to 64. The scores were categorized into two with scores ranging from 41 to 64 representing high academic self-efficacy and scores from 16 to 40 representing low academic self-efficacy. The content validity was ascertained through peer review to ensure all the items included in the instrument measure self-efficacy. The instrument was found to be reliable with the pilot data reporting a reliability coefficient of $\bigotimes=0.90$, which was higher than the internal reliability of $\otimes=0.81$ reported by Chemers, Hu \& Gracia (2001) and $\otimes=0.85$ by Zajacova, Lynch \& Espenshade (2005). Thus the reliability coefficient obtained in the pilot study was considered satisfactory to justify the use of the Academic Self-efficacy scale in this study.

\section{c. Document analysis}

Students' mathematics achievement was determined by obtaining mathematics scores for end of term II, 2013 
examination from the sampled schools. Scores were obtained in percentage and categorized as low, average and high. Scores ranging from 0 to 33 percent were classified as low, scores ranging from 34 to 66 percent were average while scores 67 to 100 percent were categorized as high achievement.

\section{Procedure}

A research permit was obtained from the National Council for Science and Technology and presented to the Machakos County Director of Education for authorization to collect data in public secondary schools in Central division, Machakos district. A pre-visit to the sampled schools was made to familiarize with the school principals and organize appropriate date and time when the researcher would revisit to sample participants and collect data.

During data collection the researcher ensured that ethical considerations were observed by first explaining the purpose of the study to the participants. Their willingness to participate in the study was obtained through the signing of the consent form. In addition, participants were assured that their responses would be confidential and will only be used for the purpose intended in the study. Data was collected by the researcher alone, by distributing questionnaires and allowing participants 30 minutes to complete and hand back the questionnaires. Mathematics scores for end of term II, 2013 
examination were obtained from the form three mathematics teachers.

Results of the study consist of descriptive statistics of means and standard deviations and inferential statistics of correlation coefficients and t-tests for independent samples. Analysis was done in sequence to the objectives of the study.

\section{Relationship between students' academic emotions and mathematics achievement.}

Students' academic emotions were analyzed based on two types the positive emotions of joy and hope and the negative emotions of boredom and shame that students may experience in mathematics. Descriptive statistics of the different domains of academic emotions are presented in table 1.

\section{Table 1}

Descriptive statistics of domains of academic emotions

\begin{tabular}{lcccccc}
\hline Domain & $\mathrm{N}$ & Range & $\begin{array}{c}\text { Min } \\
\text { imum }\end{array}$ & Maximum & Mean & $\begin{array}{c}\text { Standard } \\
\text { deviation }\end{array}$ \\
\hline Joy & 263 & 21 & 7 & 28 & 22.07 & 4.03 \\
Boredom & 257 & 21 & 7 & 28 & 12.27 & 4.15 \\
Hope & 279 & 21 & 7 & 28 & 23.10 & 3.63 \\
Shame & 271 & 19 & 7 & 26 & 12.52 & 4.05 \\
\hline
\end{tabular}


The results show that the mean for positive emotions of joy and hope was high compared to the mean for the negative emotions of boredom and shame. This implies that generally, majority of the students' found mathematics enjoyable and had hope in doing well in the subject despite the low scores they attained.

Pearson product moment correlation coefficient was used to test the hypothesis $\mathrm{H}_{01:}$ there is no significant difference between students' academic emotions and mathematics achievement. Table 2 presents the results.

\section{Table 2}

Correlation between academic emotions and mathematics achievement

\begin{tabular}{lll}
\hline $\begin{array}{l}\text { Independent } \\
\text { Variable }\end{array}$ & Test & $\begin{array}{l}\text { Dependent } \\
\text { Variable }\end{array}$ \\
\hline $\begin{array}{l}\text { Academic } \\
\text { emotions score }\end{array}$ & & $\begin{array}{l}\text { Mathematics } \\
\text { achievement } \\
\text { score(s) }\end{array}$ \\
& Pearson & 0.32 \\
& $\begin{array}{l}\text { Correlation } \\
\text { Sig. (2-tailed) }\end{array}$ & 0.00 \\
& $\mathrm{~N}$ & 220 \\
\hline
\end{tabular}


Results show that there is a positive and significant relationship between academic emotions and mathematics achievement ( $\mathrm{r}$ $=0.32, \mathrm{p}<0.05)$. The null hypothesis was therefore rejected.

\section{Relationship between academic self-efficacy and mathematics achievement}

Students' academic self-efficacy was measured using a 16 item scale. The responses were used to categorize self-efficacy as high or low pertaining to performance in mathematics. Table 3 shows the levels of academic self-efficacy obtained.

\section{Table 3}

Levels of Academic Self-Efficacy

Level of academic self-efficacy Frequency Percent

\begin{tabular}{lll}
\hline Low & 77 & 29.7 \\
High & 182 & 70.3 \\
Total & 259 & 100 \\
\hline
\end{tabular}

Students found to have high self- efficacy had scores ranging from 41 to 64 while low self-efficacy was assigned scores ranging from 16 to 40 . Results show that majority of the students reported that they had high self-efficacy beliefs in mathematics achievement while few students represented by $29.7 \%$ reported low self-efficacy in the subject. These results differ with the levels of performance in mathematics where 
many students $76.6 \%$ had low achievement in the subject hence contradicting the believe that high self-efficacy levels correspond to high achievement. The students' high self efficacy can be explained by their perseverance in the subject and efforts puts to score good grades. Mathematics being a compulsory subject in the Kenyan education curriculum, a student is likely to have high hopes in performing well and put effort into attaining a better grade.

A co-variation of the independent variable academic selfefficacy and the dependent variable mathematics achievement was done. Table 4 presents the results.

\section{Table 4}

Correlation between academic self-efficacy and mathematics achievement

\begin{tabular}{lll}
\hline Independent Variable & \multicolumn{1}{c}{ Test } & Dependent Variable \\
\hline Academic self-efficacy & & $\begin{array}{l}\text { Mathematics } \\
\text { achievement score(s) }\end{array}$ \\
& & 0.202 \\
& $\begin{array}{l}\text { Pearson } \\
\text { Correlation }\end{array}$ & \\
& Sig. & 0.01 \\
& (2-tailed) & 259 \\
\end{tabular}

Results show that that there is a positive and significant relationship between academic self-efficacy and mathematics achievement $(r=0.20, p<0.05)$, thus the null hypothesis was rejected. 


\section{Gender differences in students'academic emotions and mathematics achievement}

To determine whether gender differences exist in students' academic emotions and mathematics achievement, data obtained was used to get the mean differences in types of academic emotions between male and female students. The descriptive statistics of range, mean and standard deviation are presented and compared between male and female participants. The results are presented in Table 5.

\section{Table 5}

Mean differences in types of Academic Emotions between male and female students

\begin{tabular}{llllllll}
\hline Gender & Type of AE & N & Range & Min. & Max. Mean & $\begin{array}{c}\text { Standard } \\
\text { deviation }\end{array}$ \\
\hline \multirow{7}{*}{ Female } & Joy & 124 & 21 & 7 & 28 & 21.45 & 4.06 \\
& Boredom & 125 & 21 & 7 & 28 & 13.05 & 4.16 \\
& Hope & 135 & 21 & 7 & 28 & 22.63 & 3.76 \\
& Shame & 134 & 19 & 7 & 26 & 13.21 & 4.31 \\
Male & Joy & 139 & 18 & 10 & 28 & 22.63 & 3.95 \\
& Boredom & 132 & 18 & 7 & 25 & 11.51 & 4.01 \\
& Hope & 144 & 18 & 10 & 28 & 23.53 & 3.46 \\
& Shame & 137 & 18 & 7 & 25 & 11.84 & 3.67 \\
\hline
\end{tabular}

Key: AE- Academic Emotions

The mean differences by type of emotion show that mean 
was highest for male participants on the positive emotions of joy and hope than of the female counterparts. The means for negative emotions of boredom and shame were higher for female participants than of the male participants. Standard deviations by type of academic emotions were high for all four types of emotions among the female participants and slightly lower for the male participants.

Using t-tests for independent samples to test the hypothesis that there are no gender differences between students academic emotions and mathematics achievement, results confirmed there were significant gender differences in academic emotions $(t=-2.91, \mathrm{df} 218, \mathrm{p}<0.05)$. The difference noted was in favour of male students, an indication that male students enjoyed mathematics more than female students who reported more boredom and shame in the subject. The finding agrees with the observations of Pekrun, Frenzel, Goetz, \& Perry (2007) that perceived control and academic values differ between boys and girls resulting into different emotional experiences. They reported that even though girls and boys had received similar grades in mathematics, girls reported significantly less enjoyment and pride than boys, but more anxiety, hopelessness and shame. The current study found that girls had higher means in the negative emotions of boredom and shame while boys had higher means in the positive emotions of joy and hope. 
Data was further analyzed to determine whether gender differences existed in the domains of academic emotions. Four types of students' emotions were investigated. These were the positive emotions of joy and hope, and the negative emotions of shame and boredom.

\section{Table 6}

T-test for independent samples for gender differences in types of academic emotions

\begin{tabular}{llll}
$\begin{array}{l}\text { Type of } \\
\text { emotions }\end{array}$ & T & Df & Sig.(2-tailed) \\
\hline Joy & -1.97 & 250 & 0.05 \\
Boredom & 3.02 & 255 & 0.003 \\
Hope & -2.09 & 277 & 0.038 \\
Shame & 2.81 & 269 & 0.005 \\
\hline
\end{tabular}

Results on Table 6 reveal that all four types of academic emotions were found to have significant gender differences; joy $(\mathrm{t}=-1.97, \mathrm{df}=250, \mathrm{p}=0.05)$, boredom $(\mathrm{t}=3.02, \mathrm{df}=255$, $\mathrm{p}<0.05)$, hope $(\mathrm{t}=-2.09$, df 277, $\mathrm{p}<0.05)$, shame $(\mathrm{t}=2.81$, df $=267, p<0.05)$. The gender differences noted were in favour of male participants who reported greater enjoyment and hope in mathematics achievement. Girls scored higher in boredom and indication that they experienced little enjoyment in the subject. 


\section{Gender differences in students' self-efficacy and mathematics achievement}

A cross tabulation of students level of academic self-efficacy and gender was done and the following results obtained.

\section{Table 7}

Cross tabulation of levels of academic self-efficacy by gender

\begin{tabular}{lllllll}
\hline \begin{tabular}{l} 
Level $\begin{array}{l}\text { Lel } \\
\text { academic self- } \\
\text { efficacy }\end{array}$ \\
\cline { 2 - 6 }
\end{tabular} & \multicolumn{3}{l}{ Gender } & \multicolumn{5}{c}{ Total } \\
\cline { 2 - 6 } & Female & $\%$ & $\mathrm{~F}$ & $\%$ & $\mathrm{~F}$ & $\%$ \\
Low & 48 & 18.5 & 29 & 11.2 & 77 & 29.7 \\
High & 81 & 31.3 & 101 & 39 & 182 & 70.3 \\
Total & 129 & 49.8 & 130 & 50.2 & 259 & 100 \\
\hline
\end{tabular}

Results show that 29.7 percent of participants reported low academic self-efficacy while majority of the participants represented by $70.3 \%$ reported high academic self- efficacy. Representation of low self-efficacy by gender shows that female students had lower academic self-efficacy than the male students. It is also clear that more male students reported higher self-efficacy than their female counterparts in the same category. The hypothesis tested to determine gender differences between students academic self-efficacy and mathematics achievement gave results that there are 
significant gender differences in students academic selfefficacy $(t=-2.71, d f=257, p<0.05)$. The null hypothesis is rejected implying that there are gender differences in students' academic self-efficacy. The difference noted is in favor of the male students, who majority reported high self-efficacy than the female students.

\section{Discussion}

The current study was conducted to determine the relationship between students' academic emotions, self-efficacy and mathematics achievement. Mathematics achievement was found to be low for most of the students in all the schools studied with only few students achieving average and high scores.

Results of the study reveal that there is a significant and positive relationship between students'academic emotions and mathematics achievement. Generally, the positive emotions of joy and hope were found to have higher means than the negative emotions of boredom and shame. This means that majority of the students' found mathematics enjoyable and had hope in doing well in the subject despite the low scores they attain. This can further be explained by a situation where though a student has positive emotions they lack control in learning mathematics. The lack of control may be attributed to inability to use appropriate revision strategies and poor time management skills, such that the student hopes to perform 
well in the subject but is not adequately prepared. Another contributing factor results when the learning process and the learning environment are not stimulating enough for effective learning to take place. Though a student may enjoy mathematics and have hope in performing well, these emotions are negatively affected by the non-stimulating environment and the student ends up bored (Pekrun, 2006). Learning in a non- stimulating environment affects a students' perception of the subject and eventually poor performance results.

With regard to the relationship between self-efficacy and mathematics achievement, a significant and positive relationship was found. A higher percentage of participants reported high academic self-efficacy belief and a fewer number agreed to have low academic self-efficacy. The findings disagree with the studies of Pajares and Graham (1998) and Adem (2011) who reported that there are no gender differences in self-efficacy in mathematics achievement. Since male students were found to perform better in mathematics than females students, this difference can be attributed to the differences in self-efficacy beliefs. A student with high self- efficacy belief on competence in mathematics is likely to perform well than a student who experience low self-efficacy in the subject. High self-efficacy enables the student to persevere more in mathematics tasks, put more effort and have confidence in doing well. On the other hand, a student with low self-efficacy is likely to feel incompetent and can easily lose interest in the 
subject hence poor performance. Thus due to the low academic self-efficacy reported by girls, they are less likely to persevere in difficult mathematical tasks hence poor performance in the subject. The low academic self-efficacy and negative emotions towards mathematics negatively influence mathematics achievement among girls. To bridge the gap in gender differences in academic emotions girls need to be encouraged to develop more control on how they learn mathematics and also attach high positive values to the subject. Perceived high control and positive value attachment on mathematics results to positive academic emotions which are associated with good performance.

The results of the present study revealed that although students had higher academic self-efficacy it was found that they had below average or low academic performance. The most probable reason for low academic achievement of the students could be attributed to personal factors such as negative attitude towards mathematics subject and school factors such as poor teaching methods and non stimulating learning environment. The results also show that good performance in mathematics is not determined by the level of students' self-efficacy alone; other factors such as teachers' competence level and learning strategies used by the students may also be useful.

Significant gender differences were noted in students' academic emotions. Both positive emotions of joy and hope were found to have positive and significant gender differences. 
Similarly the negative emotions of boredom and shame had positive and significant gender differences. All the differences noted were in favor of the male students. Male students attained higher mean scores in the positive emotions of joy and hope than the females. On the other hand female students recorded higher means in the negative emotions of boredom and shame than the male students. The control value theory of emotions assumes that relations between control and value appraisal and academic emotions should be equivalent for males and females. However, perceived control and academic values differ between genders resulting to different emotional experiences (Frenzel, et al. 2007). To confirm this assumption it was found that the relationships between girls' and boys' control and value appraisal in mathematics, on one hand, and their mathematics emotions, on the other, were structurally equivalent across genders (Frenzel, Pekrun, Goetz, \& vom Hofe, 2006). However, mean scores for perceived control were substantially lower in girls. As a consequence, they reported less enjoyment in mathematics as well as more anxiety and shame. In regard to this finding girls require improvement in control strategies to enable them be in charge of their mathematics learning process so as to obtain good results. In addition to being in control their self-efficacy will also increase. Students need high value attachment to mathematics since it is a compulsory subject which is considered in career choice. Significant gender differences were also found in students' 
academic self-efficacy. $T$-test for independent samples indicated that there were positive and significant gender differences in students' academic self-efficacy. The difference was in favor of male students who were found to have higher academic self-efficacy than the female students. This can be explained by stereotype that boys do well in mathematics and sciences and girls in art subjects. Girls can do equally better by taking charge and being in control of their learning and develop positive value attachment to mathematics as a subject and careers associated with it.

Considering the two independent variables, academic emotions and self-efficacy, students' academic emotions was found to be a better predictor of mathematics achievement. Analysis shows all four types of academic emotions to be significantly related to mathematics achievement despite the gender differences noted. These gender differences can be harmonized by encouraging all students and especially girls to acquire better control strategies in learning mathematics and in addition develop high positive values towards the subject. Perceived high control and high positive value attachment to mathematics result to positive academic emotions which are associated with good performance. 


\section{References}

Adem, D. (2011). Gender-Related Beliefs and Mathematics

Performance of Pre-service PrimaryTeachers

DOI: $10.1111 / \mathrm{j} .1949-8594.2011 .00075 . x$

APHRC, (2010). Improving mathematics performance in

Kenya: How better teacher subject knowledge contribute

to academic attainment. African Population and

Health Research Centre. Policy Brief No. 18, August 2010

Bandura, A. (1986). Social foundations of thought and action:

A social cognitive theory. Englewood Cliffs, N.J.:

Prentice-Hall.

Chemers, M.M., Hu, L. \& Garcia, B.F. (2001).

Academic self-efficacy and first year college

student performance and adjustment. Journal of

Educational Psychology, 93(1), 55-64.

Frenzel, A.C, Pekrun R. \& Goetz T. (2007). Girls and mathematics -A "hopeless" issue?

A control-value approach to gender differences

in emotions towards mathematics.

European Journal of Psychology of Education

Volume 22, Issue 4, pp 497-514 
Githua, B. N. \& Mwangi, J. G. (2003). Students' mathematics self-concept and motivation to learn mathematics: relationship and gender differences among Kenya's secondary school students in Nairobi and Rift Valley Provinces. International Journal of Educational development 23(2003), 487-499

Hidi, S., \& Ainley, M. (2008). Interest and self-regulation: Relationships between two variables. In D. H. Schunk \& B. J. Zimmerman (Eds.), Motivation and self-regulated learning: Theory, research and applications (pp. 77-110). Mahwah, NJ: Lawrence Erlbaum.

Kenya Institute of Education-KIE (2002). K.C.S.E Examination Report 2001. Nairobi: KNEC.

Kulubya, M.M. \& Glencross (1997). Mathematics achievement and attitudes of senior secondary school students in Transkei, South Africa Psychological Reports: Volume 80, Issue , pp. 915-919. doi: 10.2466/ pr0.1997.80.3.915

Manoah, S.A., Indoshi, F.C, Othuon, L.O. (2011) Influence of attitude on performance of students in mathematics curriculum. Educational research vol. 2 (3) pp.965-981. 
Mbugua, Z.K., Kibet, K.,Muthaa, G.M.,\& Nkoke, G.R.

(2012). Factors contributing to students' poor performance inmathematicsat Kenya Certificate of Secondary Education in Kenya. A case study of Baringo County. American International Journal of Contemporary Research vol.2 No. 6

Momanyi, J.M., Ogoma, S.O., \& Misigo, B.L. (2011).

Gender differences in self efficacy and academic performance in science subjects among secondary school students in Lugari District, Kenya. Educational Journal of Behavioural Science.

Onsomu, E.N., Muthaka, D. Ngware, M. \& Kosimbei, G. (2006, March). Financing of Secondary Education in Kenya: Costs and Options. Kenya Institute for Public Policy Research and Analysis (KIPPRA). Retrieved from http://epaa.asu.edu/ojs/article/ view/753

Pajares, F. \& Graham L. (1998) Self-efficacy, motivation constructs, and mathematics performance of entering middle school students. http://dx.doi.org/10.1006/ceps.1998.0991

Pekrun, R., Goetz, T., Titz, W., \& Perry, R. P. (2002a). Academic emotions in students' self-regulated learning and achievement: A program of quantitative and qualitative research. Educational Psychologist, 37, 91- 106. 
Pekrun, R., Frenzel, A., Goetz, T., \& Perry, R. P. (2007).

The control-value theory of achievement emotions: An integrative approach to emotions in education. In P.A. Schutz \& R. Pekrun (Eds.), Emotions in education (pp. 13-36). San Diego: Academic Press.

Pekrun, R. and Stephens, E. J. (2010). Achievement Emotions: A Control-Value Approach. Social and Personality Psychology Compass, 4: 238-255. doi: 10.1111/j.1751-9004.2010.00259.x Rahil,M. Elias, H., Cheong, L.S., Muhamad,M. F., Noordin, N. \& Abdullah, M.C. (2006). The relationship between students' self-efficacy and their English language achievement. Jurnal Pendidik dan Pendidikan, Jil 21,61-67.

Simiyu, M.M. (2010). Influence of test anxiety and self efficacy on mathematics performance of secondary school students in Kanduyi Division of Bungoma District. Unpublished Master of Education Thesis, Kenyatta University.

Zajacova, A., Lynch, S.M., \& Espanshade, T.J. (2005). Selfefficacy, stress and academic success in college. Research in Higher Education, 46(6), 677-705. 